\title{
Stimulatory effects of fasting on vascular endothelial growth factor (VEGF) production by growing pig ovarian follicles
}

\author{
G. Galeati, M. Spinaci, N. Govoni, A. Zannoni, P. Fantinati, \\ E. Seren and C. Tamanini* \\ Dipartimento di Morfofisiologia Veterinaria e Produzioni Animali, Università di Bologna, \\ Via Tolara di Sopra, 50, 40064 Ozzano Emilia (BO), Italy
}

\begin{abstract}
The aim of this study was to investigate the effect of fasting on both vascular endothelial growth factor (VEGF) production and VEGF $m$ RNA expression in growing ovarian follicles (>5 mm in diameter) from gilts at $48 \mathrm{~h}$ after equine chorionic gonadotrophin (eCG) treatment. The concentrations of VEGF and albumin were measured in the follicular fluid of single follicles, and VEGF mRNA was determined in the follicle wall. Fasting resulted in a significant increase in VEGF concentrations in follicular fluid (20.64 \pm 0.72 versus $\left.10.79 \pm 0.86 \mathrm{ng} \mathrm{ml}^{-1}, P<0.001\right)$, but it did not affect the total amount of VEGF mRNA in the follicle wall compared with that of fed animals. However, VEGF mRNA in the theca and granulosa compartments increased and decreased, respectively, compared with that
\end{abstract}

of fed animals. The concentrations of albumin measured in follicular fluid as an index of vessel permeability were higher in fasted than in animals fed normally, most likely as a result of the increased VEGF production. Follicular steroidogenesis was impaired in fasted animals. Progesterone was the most abundant steroid in the follicular fluid and oestradiol was present in lower concentrations, thus indicating an alteration in the steroidogenic enzymatic cascade. In conclusion, fasting induces an increase in both VEGF production and vessel permeability. Such a reaction is unable under severe food deprivation to preserve follicle function, but may represent a mechanism that regulates blood vessel extension and distribution in relation to tissue requirements and availability of systemic nutrient.

\section{Introduction}

Angiogenesis, a process that involves the formation of new vessels from pre-existing vessels, is very active during different phases of development and is downregulated in most adult organs and tissues. In contrast, neoplastic formations are characterized by a rapid and extensive gowth. Physiological angiogenesis occurs in the adult female within the uterus, placenta, mammary gland and ovary (Pepper, 1997; Risau, 1997). Ovarian angiogenesis depends on the different phases of the oestrous cycle, is characterized by dynamic changes in the vascular architecture and is ruled by a variety of interactions among the different types of cell, not just endothelial cells (Grazul-Bilska et al., 1997). Vascular endothelial growth factor (VEGF) is a major regulator of angiogenesis (Fraser et al., 2000; Wulff et al., 2001) and its production by ovarian cells has been demonstrated extensively (Barboni et al., 2000; Basini et al., 2000; Berisha et al., 2000). VEGF is effective in both stimulating vessel growth and in increasing endothelial permeability, thus favouring the uptake of nutrients by the developing

${ }^{*}$ Correspondence

Email: tamanini@vet.unibo.it tissues (Gomez et al., 2002). In pig follicles, VEGF production is stimulated by gonadotrophins (Mattioli et al., 2001) and is positively related to follicle size (Grasselli et al., 2002), thus further confirming its fundamental role in the development of a rich vessel network within the follicle wall. Among the other factors involved in stimulating VEGF secretion, the progressive decrease of oxygen tension (Bianco et al., 2003) in the follicle (as a result of the increasing metabolic rate) and the nutrient deprivation (as a result of the reduction in blood supply; Abcouwer et al., 2002; Zakrzewicz et al., 2002) appear to play a role. Therefore, it is likely that the regulation of blood vessel growth could depend, at least in part, on local availability of oxygen and nutrients and the reduction of these parameters is possibly effective in actively stimulating VEGF output by follicular cells. In particular, recent findings (Prunier and Quesnel, 2000a; Almeida et al., 2000) indicate that adequate nourishment is essential for follicular development in the pig; furthermore, nutrient deprivation has been clearly demonstrated to impair ovarian activity and the whole reproductive process markedly in different species (Boland et al., 2001; Engelbregt et al., 2002).

The aim of this study was to verify whether VEGF production and VEGF mRNA expression during follicular 
development in pigs are affected by fasting and whether fasting is effective in influencing steroidogenesis in follicular cells.

\section{Materials and Methods}

\section{Animals and hormonal stimulation protocols}

Ten prepubertal Large White $\times$ Duroc gilts, average of $94 \pm 1.47 \mathrm{~kg}$ (mean \pm SEM) body weight, were randomly allocated to two experimental groups: (i) group A, normal feeding with a commercial diet, treated with $1250 \mathrm{iu}$ equine chorionic gonadotrophin (eCG; Folligon, Intervet Int., Boxmeer); and (ii) group B, $72 \mathrm{~h}$ of fasting with water available at all times, treated with 1250 iu eCG at $24 \mathrm{~h}$ after the beginning of fasting regimen. Ovariectomy was carried out in both groups at $48 \mathrm{~h}$ after eCG stimulation when follicles with a diameter $>5 \mathrm{~mm}$, as shown previously, have already activated an intense synthesis of VEGF (Mattioli et al., 2001). Ovaries were recovered by laparotomy from animals pre-anaesthetized by an injection of azaperone (240 mg per gilt; Stresnil, Janssen, Beerse) and atropine sodium salt (2 mg per gilt; Industria Galenica Senese, Monteroni D'Arbia, Siena), and maintained under thiopental sodium (1.5 g per gilt; Pentothal Sodium, Gellini, Aprilia, Latina) anaesthesia. All protocols had been previously approved by the Ethical Committee of the University of Bologna. Immediately after removal, the ovaries were transported to the laboratory where single follicles were isolated in dissection medium (Dulbecco's phosphate buffer medium supplemented with $0.4 \%$ BSA) under a stereomicroscope. After measuring the diameter of the follicles with a calibrated grid, healthy follicles, as indicated by their translucid appearance, their limpid follicular fluid and extensive wall vascularization (Dailey et al., 1975), with a diameter of $>5 \mathrm{~mm}$ were dried on a tissue paper to eliminate any trace of medium and opened in a $35 \mathrm{~mm}$ Petri dish to collect follicular fluid. The samples of follicular fluid were then frozen individually until assayed for VEGF, albumin and steroid content (progesterone, testosterone and oestradiol). The follicle wall obtained from each follicle was then transferred in dissection medium, mechanically divided in the two components, theca and granulosa, as described by Barboni et al. (2000) and stored at $-80^{\circ} \mathrm{C}$ until measurement of VEGF mRNA. All the cells were frozen within $1 \mathrm{~h}$ from the surgical removal of the ovaries.

\section{VEGF assay}

Samples of follicular fluid were measured for VEGF content by a specific enzyme-linked immunosorbent assay (ELISA, Quantikine, R\&D Systems, Minneapolis, $M N$ ) previously validated for the measurement of pig VEGF (Barboni et al., 2000; Mattioli et al., 2001). This highly specific sandwich assay recognizes VEGF 165 as well as VEGF 121, whereas it exhibits negligible crossreactivity with all cytokines and growth factors tested. A 96-well plate reader (Biomek 1000, Beckman Instruments, Fullerton, CA) set to read at $450 \mathrm{~nm}$ emission was used to quantify the results. The sensitivity of the assay was equivalent to $5 \mathrm{pg} \mathrm{ml}^{-1}$ follicular fluid. Intra-assay coefficients of variation for replicate determinations of pooled follicular fluid samples with low (3.52 $\pm 0.12 \mathrm{ng} \mathrm{ml}^{-1} ; \quad n=10$ replicates) and high $\left(12.43 \pm 0.44 \mathrm{ng} \mathrm{ml}^{-1} ; n=8\right.$ replicates) VEGF concentrations were 6.4 and $7.1 \%$, respectively; interassay coefficients of variation for the same samples with low and high VEGF concentrations were 8.5 and $7.4 \%$ (five assays). The concentrations of VEGF in samples of follicular fluid are expressed as $\mathrm{ng} \mathrm{ml}^{-1}$.

Expression of VEGF mRNA was evaluated as described by Barboni et al. (2000) and Mattioli et al. (2001). Briefly, RNA isolation was performed on granulosa and theca cells, previously isolated from the follicle wall, using a Tri-Pure isolation kit (Roche Diagnostics $\mathrm{GmbH}$, Mannheim). The amount and purity of nucleic acid extracts were determined using a spectrophotometer and RNA integrity was tested by PCR of $\beta$-actin.

VEGF primers were selected on the basis of a bovine VEGF sequence (GenBank AN M32976) and they were 5'-CCT GAT GCG GTG CGG GGG CT-3' (VEGF-1 nucleotides 779-798) and 5'-TGG TGG TGG CGG CGG CTA TG-3' (VEGF-2 complementary to nucleotides 1197-1216). These primers were able to amplify all VEGF isoforms; in fact their position on the sequence is before and after the splicing site.

Primers for pig $\beta$-actin were $5^{\prime}$-ATC GTG CGG GAC ATC AAG GA-3' (ActSS-1) and 5'-AGG AAG GAG GGC TGG AAG AG-3' (ActSS-2). RT-PCR reactions were conducted as described by Barboni et al. (2000) and Mattioli et al. (2001). In brief, equal amounts of total RNA $(0.5 \mu \mathrm{g})$ were retro-transcribed using avian myeloblastosis virus-reverse transcriptase (AMV) followed by PCR reactions for VEGF and $\beta$-actin. Products of amplification were separated on agarose gel $(1.5 \%)$ using electrophoresis and visualized by ethidium bromide staining. The specificity of RT-PCR was confirmed by performing Southern blot analysis using an oligo probe of 40mer (complementary to VEGF nucleotides 850-890) labelled with a non-radioactive system (Digoxigenin oligonucleotide 3'-end labelling kit, Roche) and revealed by chemiluminescent detection. The relative densities of ethidium bromide staining and chemiluminescence were determined by densitometry (Fluor-S-Max, Bio-Rad, Hercules, CA). $\beta$-actin mRNA has been found in pig follicle cells with contents that are independent of follicle status and size (Tilly et al., 1992) and its expression is not affected by growth factors or gonadotrophins (LaPolt et al., 1990; Weiner and Dias, 1993). Therefore, VEGF mRNA contents were normalized on the basis of $\beta$-actin mRNA content and expressed in arbitrary units. 


\section{Steroid determination in follicular fluid}

Validated radioimmunoassays were used for the measurement of progesterone and oestradiol (Tamanini et al., 1985), and testosterone (Gaiani et al., 1984). In brief, aliquots of follicular fluid $(10 \mu \mathrm{l})$ from each follicle were diluted with 10 volumes of phosphate buffer and then extracted with $5 \mathrm{ml}$ diethyl ether. After centrifugation (500 $\boldsymbol{g}$ for $5 \mathrm{~min}$ ), ether was collected and dried under a $\mathrm{N}_{2}$ stream. Dried ether extracts were resuspended in $800 \mu \mathrm{l}$ phosphate buffer and sets of two $100 \mu \mathrm{l}$ aliquots were then assayed for steroid content. For progesterone, the mean intra-assay ( $n=5$ samples) and interassay $(n=4$ assays) coefficients of variation for diluted follicular fluid samples with low $\left(0.68 \pm 0.03 \mathrm{ng} \mathrm{ml}^{-1}\right)$ and high $\left(8.23 \pm 0.09 \mathrm{ng} \mathrm{ml}^{-1}\right)$ concentrations were 6.1 and 5.9 and 8.2 and $8.8 \%$, respectively, and the assay sensitivity was $7.2 \mathrm{pg} \mathrm{ml}^{-1}$. For testosterone, mean intra-assay ( $n=5$ samples) and interassays ( $n=4$ assays) coefficients of variation for diluted follicular fluid samples with low $\left(0.4 \pm 0.02 \mathrm{ng} \mathrm{ml}^{-1}\right)$ and high $\left(3.2 \pm 0.08 \mathrm{ng} \mathrm{ml}^{-1}\right)$ concentrations were 7.3 and 6.9 and 10.1 and $10.5 \%$, respectively, and the sensitivity of the assay was $2.9 \mathrm{pg}$ $\mathrm{ml}^{-1}$. For oestradiol, the coefficients of variation (intraassay, $n=5$ samples; interassay, $n=4$ assays) were 5.2 and $10.8 \%$ (low sample: $0.3 \pm 0.02 \mathrm{ng} \mathrm{ml}^{-1}$ ) and 5.4 and $11.0 \%$ (high sample: $5.2 \pm 0.07 \mathrm{ng} \mathrm{ml}^{-1}$ ), and assay sensitivity was $2.1 \mathrm{pg} \mathrm{m}^{-1}$. The concentrations of steroids are expressed as $\mathrm{ng} \mathrm{m}^{-1}$ follicular fluid.

\section{Albumin concentrations in follicular fluid}

As angiogenic factors such as VEGF do not simply increase the network of blood vessels but can condition the permeability of pre-existing vessels, follicular fluid concentrations of albumin, a plasma protein at the edge of the exclusion size for the capillary wall (Fu and Shen, 2003), was measured to assess potential modifications in the permeability of blood vessels of the follicle wall. Albumin concentrations were measured using a spectrophotometer $(600 \mathrm{~nm})$ in $5 \mu \mathrm{l}$ follicular fluid by the bromocresol purple binding method (Albumin BCPSigma, Chemical Co., St Louis, MO) according to the manufacturer's instructions. The sensitivity of the assay was $0.5 \mathrm{mg} \mathrm{ml}^{-1}$; the within-run ( $n=5$ samples) and run-to-run ( $n=4$ assays) coefficients of variation for a low $\left(2.6 \mathrm{mg} \mathrm{ml}^{-1}\right)$ and a high $\left(12.1 \mathrm{mg} \mathrm{ml}^{-1}\right)$ concentration sample were 3.5 and 4.2 and 5.6 and $6.0 \%$, respectively.

\section{Statistical analysis}

Data were analysed by JMP (SAS Institute Inc) and Mathematica (Wolfram Research Inc) programs. A preliminary statistical comparison between treatments was based on evaluation of SEM at 95\% probability (significance level). The analysis was completed by a second order factorial variance analysis for all the observed responses (VEGF and VEGF mRNA contents, albumin and steroids) to discriminate between treatment, animal, follicle size and their second order interactions as source of variation. The factorial model (generalized linear model) can be represented as $y_{\mathrm{ijkl}}=\mu+\alpha_{\mathrm{i}}+\beta_{\mathrm{j}}+$ $\gamma_{l}+\alpha \beta_{i j}+\alpha \gamma_{i l}+\beta \gamma_{j l}+\varepsilon_{i j k l}$, where $y_{i j k l}$ represents the response variable (VEGF and mRNA contents), $\mu$ is the overall mean and $\alpha_{i}, \beta_{j}, \gamma_{l}$ are the animal, the treatment and the follicle size effect, respectively, with their interactions $\left(\alpha \beta_{i j}, \alpha \gamma_{i l}, \beta \gamma_{j l}\right)$, and $\varepsilon_{i j k l}$ is the error term. A third order interaction was omitted from the model because this is not significant for any of the observed responses and also for simplicity. The relationship between VEGF concentration and follicle size was further analysed by linear fitting (least square method) of these variables for each treatment.

\section{Results}

\section{Follicular fluid concentrations of VEGF}

The mean number of large follicles (mean diameter of $5.76 \pm 0.15 \mathrm{~mm}$ ) isolated from the ovaries of gilts fed with a normal plane of nutrition at $48 \mathrm{~h}$ after treatment with eCG was $8.6 \pm 2.2$ (mean isolated follicles per gilt \pm SEM; $n=44$ ); fasting did not modify the proportion of isolated large healthy follicles $(9.8 \pm 1.6$ follicles per gilt; $n=49$ ) or their mean diameter (5.63 \pm $0.27 \mathrm{~mm}$ ). The mean concentration of VEGF in follicular fluid of animals that were fed normally was $10.79 \pm 0.86 \mathrm{ng} \mathrm{ml}^{-1}$; fasting significantly $(P<0.001)$ increased VEGF concentration, which reached mean values of $20.64 \pm 0.72 \mathrm{ng} \mathrm{ml}^{-1}$. In both groups of animals, a significant $(P<0.05)$ treatment by female (but not treatment by follicle size) interaction was observed. The correlation between VEGF content in follicular fluid and follicle size in both normally fed and fasted gilts is reported (Fig. 1).

\section{Follicular fluid concentrations of albumin}

Follicular fluid concentrations of albumin in normally fed animals averaged $8.48 \pm 0.34 \mathrm{mg} \mathrm{ml}^{-1}$; albumin concentration in follicular fluid from follicles isolated from fasted animals reached significantly higher values $\left(9.48 \pm 0.24 \mathrm{mg} \mathrm{ml}^{-1} ; P<0.05\right)$. Albumin concentrations were not influenced by follicle size or by the gilt.

\section{VEGF mRNA content in granulosa and theca compartments}

VEGF RT-PCR amplification confirmed that the two major isoforms (VEGF 164 and VEGF 120) were expressed both in theca and granulosa compartments of large follicles in pigs, as reported by Barboni et al. (2000). The overall content of VEGF mRNA in the follicle wall was similar in normally fed and fasted animals $(557.35 \pm 21.88$ versus $591.97 \pm 33.36$ arbitrary units, respectively), but fasting influenced its distribution. In 


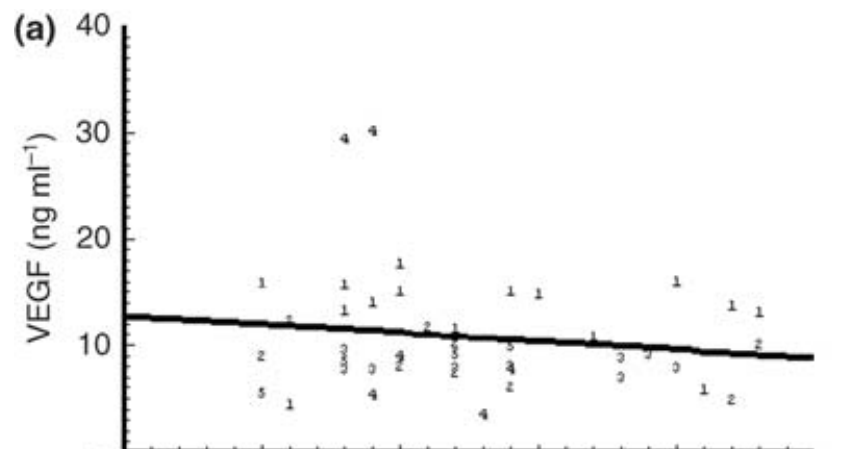

(b)

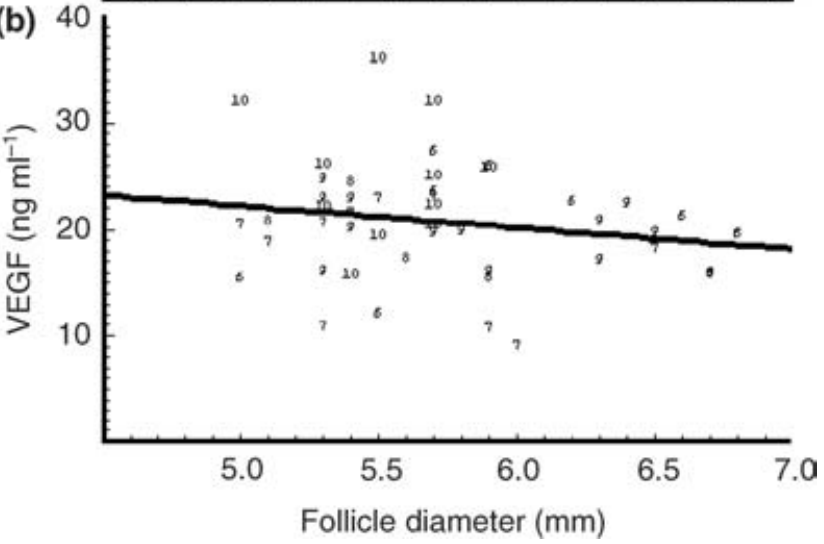

Fig. 1. Correlation between the concentration of vascular endothelial growth factor (VEGF) in follicular fluid ( $\mathrm{ng} \mathrm{ml}^{-1}$ ) and the size of the follicle $(\mathrm{mm})$ in (a) normally fed and (b) fasted gilts; the numbers indicate the follicles of a given animal $(n=5$ per group). The correlation coefficients are close to $0 \quad(r=0.02$, $P<0.05$ and $r=0.03, P<0.01$ for normally fed and fasted gilts, respectively) for both groups, thus indicating a lack of correlation between VEGF concentrations and follicle size.

fact, the content of VEGF mRNA in normally fed gilts was higher in the granulosa than in the theca compartment (mean values: $438.92 \pm 26.23$ and $118.43 \pm$ 7.55 arbitrary units, respectively; $P<0.01)$, whereas fasting significantly increased the content of VEGF mRNA in the theca cells (up to $262.75 \pm 24.78$ arbitrary units, $P<0.01)$ and reduced VEGF mRNA expression in granulosa cells $(329.12 \pm 40.80$ versus $438.92 \pm 26.23$, $P<0.05)$. As a result, mRNA content in the two follicular compartments was similar (that is, $329.12 \pm 40.80$ and $262.75 \pm 24.78$ arbitrary units in granulosa and theca layer, respectively). The ratio between granulosa and theca mRNA content revealed that VEGF production is polarized in the follicular wall of control animals (ratio granulosa:theca VEGF mRNA content $R=3.71$ ), and this condition is completely removed during fasting $(R=$ 1.25). Neither gilt nor follicle size effect was observed.

\section{Steroid production}

Intrafollicular concentrations of steroids were markedly affected by the plane of nutrition (Fig. 2). Under

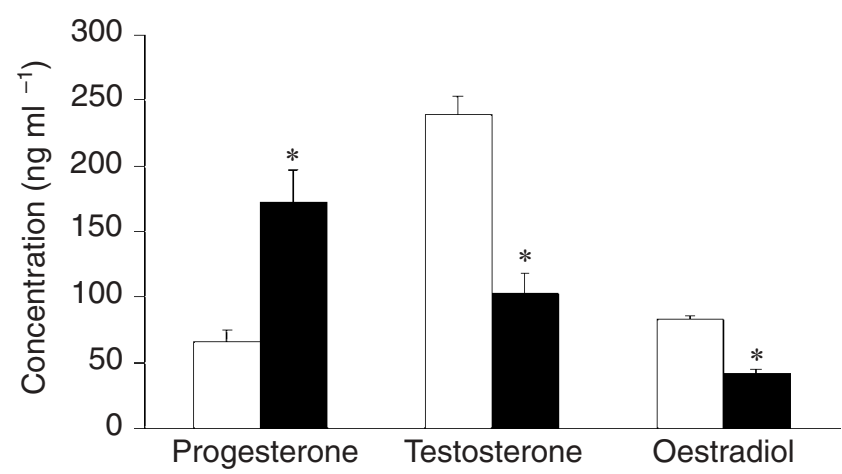

Fig. 2. Steroid concentration (ng $\mathrm{ml}^{-1}$ ) in follicular fluid from follicles isolated from normally fed $(\square)$ and fasted (ם) gilts. Asterisks indicate significant differences $(P<0.05)$ between the concentrations of the same hormone.

control conditions, testosterone concentration in follicular fluid was $238.97 \pm 13.71 \mathrm{ng} \mathrm{ml}^{-1}$, and oestradiol and progesterone concentrations were $82.84 \pm 3.11$ and $65.72 \pm 8.85 \mathrm{ng} \mathrm{ml}^{-1}$, respectively. Steroidogenesis in fasted gilts was markedly reduced. Testosterone and oestradiol decreased to $102.95 \pm 15.59$ and $42.36 \pm 2.78 \mathrm{ng} \mathrm{ml}^{-1}$, which was significantly lower than concentrations observed in control animals $(P<$ 0.05 and $P<0.001$, respectively), whereas progesterone increased to $171.91 \pm 24.94 \mathrm{ng} \mathrm{ml}^{-1}(P<0.05)$. In any case, the overall steroid output obtained by the sum of the concentrations of oestradiol, testosterone and progesterone was not affected by feed regimens (about 317 versus $387 \mathrm{ng} \mathrm{m}^{-1}$ in fasted versus normally fed animals, respectively). No effects were observed for any steroid with respect to female, follicle size and relevant interactions are concerned.

\section{Discussion}

Production of VEGF by the follicle wall increases as the follicle develops and its functional status changes (Basini et al., 2000; Barboni et al., 2000). Treatment with gonadotrophins is effective in further stimulating VEGF output (Mattioli et al., 2001). These findings strongly indicate that VEGF plays a major role in follicular growth, which is associated with the development of an extensive vascular network (Otani et al., 1999; Mattioli et al., 2001). In addition, Grasselli et al. (2002) suggested that VEGF supports follicular development by stimulating the proliferation of granulosa cells from large ovarian follicles in pigs.

VEGF is mainly secreted by granulosa cells, whereas the theca layer seems responsible only for a constant baseline production. Mattioli et al. (2001) suggested that the accumulation of VEGF in the follicular fluid creates an angiogenic gradient that favours the development of a blood vessel network mainly in the proximity of the basal membrane (which cannot be crossed by vessels) 
dividing the granulosa from the theca layer. This network is obviously involved in exchanging both metabolites and gases with granulosa cells. As already mentioned, there is evidence that hypoxic conditions powerfully stimulate VEGF production (Neeman et al., 1997; Pham et al., 2002); on the contrary, no data are available on the effect of food deprivation on VEGF output, even though angiogenesis is stimulated by nutrients shortage (Abcouwer et al., 2002; Zakrzewicz et al., 2002). The results from the present study indicate that fasting strongly stimulates VEGF production compared with that of normally fed animals, thus allowing a marked acceleration of the angiogenic process. On the basis of the expression of VEGF mRNA in theca and granulosa layers, the contribution of the two different types of cell to VEGF production seems to be markedly influenced by fasting. In fact, although gonadotrophins (that is, eCG and hCG) are mainly effective at the granulosa cell (Barboni et al., 2000; Wang et al., 2002), fasting primarily increases VEGF expression in the theca compartment while reducing VEGF mRNA contents in granulosa cells; VEGF then probably accumulates in the follicular cavity. The reason for this effect remains obscure. One possible explanation is that the abundant irrigation of the theca layer makes these cells more sensitive to the reduction in nutrients, thus activating a prompt compensatory process of adaptation through a higher production of the angiogenic factor. As demonstrated in the present study by the higher concentration of albumin in follicular fluid from fasted gilts, VEGF seems to be effective not only in stimulating vessel growth but also in augmenting vessel permeability, as compared with that from control animals (Gomez et al., 2002; Breslin et al., 2003). In fact, VEGF is also known as vascular permeability factor (VPF) because of its ability to induce vascular leakage (Senger et al., 1983; Geva and Jaffe, 2000), which is a crucial step in angiogenesis. The increase in vascular permeability is likely to contribute actively to the compensatory mechanism of adaptation of the growing follicles to a condition of reduced supply of nutrients.

Data obtained on steroid concentrations in follicular fluid indicate that feed restriction severely affects steroidogenesis even though the total concentrations of sex hormones was not different between the two groups of animals. The significant decrease in oestradiol concentrations in follicular fluid from fasting animals is consistent with the findings of Cosgrove et al. (1992) and by Prunier and Quesnel (2000a) indicating that feed restriction impairs oestradiol synthesis; the parallel reduction of testosterone (the main oestradiol precursor) is in accordance with expectation, in that its low concentrations in underfed gilts may account for a decrease in oestradiol. In addition, in vitro experiments by Grasselli et al. (2002) indicate that VEGF exerts an inhibitory effect on oestradiol output by granulosa cells from large ovarian follicles in pigs. Therefore, it can be assumed that fasting negatively influences oestradiol production both directly and through the stimulation of VEGF production (which, in turn, inhibits oestradiol synthesis). Surprisingly, fasting increased progesterone concentrations; there is no convincing explanation for this effect, but an impairment of the mechanisms regulating progesterone metabolism cannot be excluded. Furthermore, plasma progesterone concentrations that are significantly higher in feedrestricted than in normally fed gilts have been reported (Prunier and Quesnel, 2000b), possibly as a consequence of a decreased metabolic clearance of the steroid. In conclusion, data on steroidogenesis allow us to speculate that acute feed restriction affects steroid production by possibly disassembling its biosynthetic pathways, even though the overall potential of synthesis does not seem to be substantially modified.

Collectively, the results from the present study indicate that fasting activates compensatory mechanisms which, through stimulation of VEGF production, are directed to increase both vessel extension and permeability to optimize nutrient supply to the growing follicles; nevertheless, these mechanisms do not seem to be effective in preserving physiological steroidogenesis, which is somehow impaired. However, it should be taken into account that feed restriction in our experimental model was particularly severe, thus preventing the follicle from properly adjusting the vessel network according to the availability of nutrients and oxygen.

This work was supported by a MIUR COFIN grant.

\section{References}

Abcouwer SF, Marjon PL, Loper RK and Vander Jagt DL (2002) Response of VEGF expression to amino acid deprivation and inducers of endoplasmic reticulum stress Investigative Opthalmology and Visual Science 43 2791-2798

Almeida FRCL, Kirkwood RN, Aherne FX and Foxcroft GR (2000) Consequences of different patterns of feed intake during the estrous cycle in gilts on subsequent fertility Journal of Animal Science 78 1556-1563

Barboni B, Turriani M, Galeati G, Spinaci M, Bacci ML, Forni M and Mattioli $\mathbf{M}$ (2000) Vascular endothelial growth factor production in growing pig antral follicles Biology of Reproduction 63 858-864

Basini G, Grasselli F, Cavalli V and Tamanini C (2000) Effects of b-FGF, IGF-I and TNF $\alpha$ on VEGF production by swine granulosa cells Journal of Reproduction and Fertility Supplement $\mathbf{2 6}$ Abstract 47

Berisha B, Schams D, Kosmann M, Amselgruber W and Einspanier R (2000) Expression and localisation of vascular endothelial growth factor and basic fibroblast growth factor during the final growth of bovine ovarian follicles Journal of Endocrinology 167 371-382

Bianco F, Basini G, Grasselli F and Tamanini C (2003) PO2 quantification in swine follicular fluid Reproduction Abstract Series 30 P58 (Abstract)

Boland MP, Lonergan P and O'Callaghan D (2001) Effect of nutrition on endocrine parameters, ovarian physiology, and oocyte and embryo development Theriogenology 55 1323-1340

Breslin JW, Pappas PJ, Cerveira JJ, Hobson RW and Duran WN (2003) VEGF increases endothelial permeability by separate signalling pathways involving ERK-1/2 and nitric oxide American Journal of Physiology: Heart and Circulatory Physiology 284 H92-H100

Cosgrove JR, Tilton JE, Hunter MG and Foxcroft GR (1992) Gonadotropinindependent mechanisms participate in ovarian responses to realimentation in feed-restricted prepubertal gilts Biology of Reproduction 47 $736-745$ 
Dailey RA, Clark JR, First NL, Chapman AB and Casida LE (1975) Loss of follicles during the follicular phase of the estrous cycle of swine as affected by genetic group and level of food intake Journal of Animal Science 41 835-841

Engelbregt MJ, Van Weissenbruch MM, Popp-Snijders C and Delemarrevan de Waal HA (2002) Delayed first cycle in intrauterine growthretarded and postnatally undernourished female rats: follicular growth and ovulation after stimulation with pregnant mare serum gonadotropin at first cycle Journal of Endocrinology 173 297-304

Fraser HM, Dickson SE, Lunn SF, Wulff C, Morris KD, Carroll VA and Bicknell R (2000) Suppression of luteal angiogenesis in the primate after neutralization of vascular endothelial growth factor Endocrinology 141 995-1000

Fu BM and Shen S (2003) Structural mechanisms of acute VEGF effect on microvessel permeability American Journal of Physiology: Heart and Circulatory Physiology 284 H2124-H2135

Gaiani R, Chiesa F, Mattioli M, Nannetti G and Galeati G (1984) Androstenedione and testosterone concentrations in plasma and milk of the cow throughout pregnancy Journal of Reproduction and Fertility 70 55-59

Geva E and Jaffe RB (2000) Role of vascular endothelial growth factor in ovarian physiology and pathology Fertility and Sterility 73 429-438

Gomez R, Simon C, Remohi J and Pellicer A (2002) Vascular endothelial growth factor receptor-2 activation induces vascular permeability in hyperstimulated rats, and this effect is prevented by receptor blockade Endocrinology 143 4339-4348

Grasselli F, Basini G, Bussolati S and Tamanini C (2002) Effects of VEGF and bFGF on proliferation and production of steroids and nitric oxide in porcine granulosa cells Reproduction in Domestic Animals 37 362-368

Grazul-Bilska AT, Redmer DA and Reynolds LP (1997) Cellular interactions in the corpus luteum Seminar in Reproductive Endocrinology 15 383-393

LaPolt PS, Piquette GN, Soto D, Sincich C and Hsueh AJ (1990) Regulation of inhibin messenger ribonucleic acid levels by gonadotropins, growth factors and gonadotropin-releasing hormone in cultured rat granulosa cells Endocrinology 127 823-831

Mattioli M, Barboni B, Turriani M, Galeati G, Zannoni A, Castellani G, Berardinelli P and Scapolo PA (2001) Follicle activation involves vascular endothelial growth factor production and increased blood vessel extension Biology of Reproduction 65 1014-1019

Neeman M, Abramovitch R, Schiffenbauer YS and Tempel C (1997) Regulation of angiogenesis by hypoxic stress: from solid tumours to the ovarian follicle International Journal of Experimental Pathology $\mathbf{7 8}$ 57-70

Otani N, Minami S, Yamoto M, Shikone T, Otani H, Nishima R, Otani T and Nakana R (1999) The vascular endothelial growth factor/fms-like tyrosine kinase system in human ovary during the menstrual cycle and early pregnancy Journal of Clinical Endocrinology and Metabolism $\mathbf{8 4}$ 3845-3851
Pepper MS (1997) Manipulating angiogenesis. From basic science to the beside Arteriosclerosis Thrombosis and Vascular Biology 17 605-619

Pham I, Uchida T, Planes C, Ware LB, Kaner R, Matthay MA and Clerici C (2002) Hypoxia upregulates VEGF expression in alveolar epithelial cells in vitro and in vivo. American Journal of Physiology: Lung Cellular and Molecular Physiology 283 1133-1142

Prunier A and Quesnel H (2000a) Influence of the nutritional status on ovarian development in female pigs Animal Reproduction Science 60-61 185-197

Prunier A and Quesnel H (2000b) Nutritional influences on the hormonal control of reproduction in female pigs Livestock Production Science 63 $1-16$

Risau W (1997) Mechanisms of angiogenesis Nature 386 671-674

Senger DR, Galli SJ, Dvorak AM, Perruzzi CA, Harvey VS and Dvorak HF (1983) Tumor cells secrete a vascular permeability factor that promotes accumulation of ascites fluid Science 219 983-985

Tamanini C, Bono G, Cairoli F and Chiesa F (1985) Endocrine responses induced in anestrous goats by the administration of different hormones after fluoregestone acetate treatment Animal Reproduction Science 9 357-364

Tilly JL, Kowalski KI, Schomberg DW and Hsueh AJ (1992) Apoptosis in atretic ovarian follicles is associated with selective decreases in messanger ribonucleic acid transcripts for gonadotropin receptors and cytochrome P450 aromatase Endocrinology 131 1670-1676

Wang TH, Horng SG, Chang CL, Wu HM, Tsai YJ, Wang HS and Soong YK (2002) Human chorionic gonadotropin-induced ovarian hyperstimulation syndrome is associated with up-regulation of vascular endothelial growth factor Journal of Clinical Endocrinology Metabolism 87 3300-3308

Weiner KX and Dias JA (1993) Regulation of ovarian ornithine decarboxylase activity and its mRNA by gonadotropins in the immature rat Molecular Cell Endocrinology 92 195-199

Wulff C, Wiegand SJ, Saunders PTK, Scobie GA and Fraser HM (2001) Angiogenesis during follicular development in the primate and its inhibition by treatment with truncated Flt-1-Fc (vascular endothelial growth factor trap (A40)) Endocrinology 147 3244-3256

Zakrzewicz A, Secomb TW and Pries AR (2002) Angioadaptation: keeping the vascular system in shape News Physiological Sciences $\mathbf{1 7}$ 197-201

Received 4 April 2003.

First decision 21 May 2003.

Revised manuscript received 10 July 2003.

Accepted 18 July 2003. 